\title{
Two princes
}

Shaun Sellars continues his series on ethical dilemmas in dentistry

which appears in every second issue of the BDJ.

When is $£ 50$ million not $£ 50$ million?

When it's new money promised to NHS dentistry.

Okay, maybe I won't give up the day job for a career in comedy just yet, but the newly announced funding injection into out-ofhours dentistry doesn't pass the smell test. Much akin to the promised 40 new hospitals and 50,000 new nurses, this figure sounds impressive, but the reporting doesn't seem to match the reality of the situation.

The funding is specifically designated for providing out-of-hours services on top of existing contract provisions. That is, it's only available if you can commit to extra 3.5-hour sessions either early morning, late at night or over the weekends. There's a significant carrot of an enhanced sessional fee being dangled to encourage uptake. Still, for a service that's currently struggling to meet the $85 \%$ target for their regular contract, it's hard to see how this offer is going to be taken up by many. The vast majority of dentists I've discussed this with have no intention of taking up the offer, either because they're struggling to hit that target or simply they don't have the time or energy to do so without burning out. And if the straw poll of the nurses I work with is indicative, even if the dentists wanted to work, there's no way we'd be able to anyway.

However, the $£ 50$ million figure is an excellent piece of spin by the NHS. Despite being only around $2 \%$ of the NHS dental budget, the amount is large enough to prick the ears of the media, who have taken the story and run with it. It places the emphasis of service provision firmly on the dentists, with the implication that if the offer isn't taken up, it's our fault rather than a result of a broken system. And it's gained enough traction to become a 'zombie statistic', which can be dragged up in the future whenever discussing dental funding.

Out-of-hours care isn't the only piece of spin in the press at the moment. Recently, Dental Protection appealed a case on behalf of their dental director regarding vicarious liability. The press release from the indemnity company reads as a victory for themselves and their client, removing the risk of vicarious liability claims against principals. ${ }^{1}$ Conversely, when reading the report from the barristers for the claimant, it becomes clear that Dental Protection's appeal

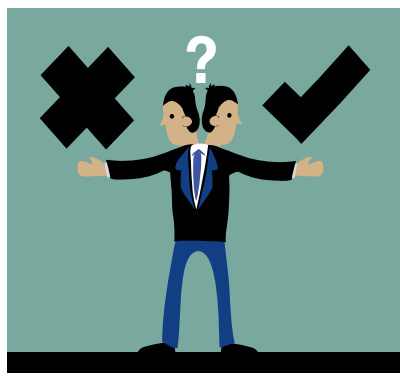

was rejected and that patients are potentially free to pursue legal cases against practices rather than independent associates in moving forward. ${ }^{2}$ While both press releases may be factually accurate, Dental Protection's conveniently fails to mention that they lost the case.

Spin has dominated the political sphere for years, more recently evolving into the phenomenon of 'fake news'. One would have hoped that professional dental reporting would have escaped from this form of factual posturing, but it appears not. Without basic facts being reported correctly, we become dental tabloids. The profession and the patients we serve deserve better.

\section{References}

1. Dental Protection. Dental Protection member successfully fights vicarious liability claim at Court of Appeal. 2022. Available at https://www. dentalprotection.org/uk/articles/dental-protectionmember-successfully-fights-vicarious-liability-claimat-court-of-appeal (accessed February 2022).

2. Old Square Chambers. Rattan v Hughes - Case Note. 2022. Available at https://oldsquare.co.uk/rattan-vhughes-case-note/ (accessed February 2022).

\section{Inaugural College Medal awarded to lan Mills}

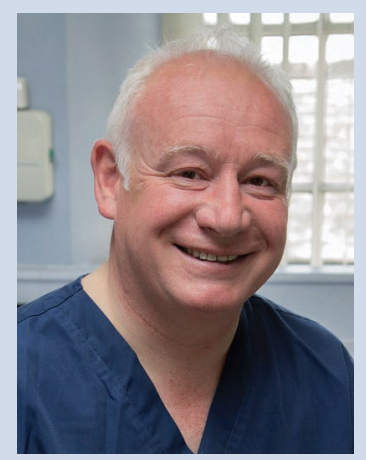

Ian Mills has become the first ever recipient of the prestigious College Medal, the highest honour bestowed by the College of General Dentistry (CGDent).

Reserved to no more than one recipient per year, the College Medal succeeds the Faculty Medal, which was previously awarded by the Faculty of General Dental Practice UK (FGDP) to just four individuals. It is conferred for exceptional service of the dental profession and its patients in a manner aligned with the values and mission of the College and both members and nonmembers are eligible for consideration.

Dr Mills has received the award in recognition of his considerable contributions to the profession over many years, including through the College and previously the Faculty, in particular his exemplary leadership at the height of the coronavirus pandemic, his pivotal roles in establishing the CGDent and securing the FGDP's transfer into it last year and his promotion of greater equality, diversity and inclusion in the dental professions.

Dr Mills is an Ambassador, Founder, Fellow and former Trustee of the College of General Dentistry and has been instrumental in the establishment and progression of its career pathways programme. A Fellow of the International College of Dentists, the Higher Education Academy and the Faculty of Dental Surgery of the Royal College of Physicians and Surgeons of Glasgow, he is a former Trustee of the Royal College of Surgeons of England. He continues to work as a partner at Torrington Dental Practice in North Devon, an eight-surgery mixed NHS and private practice. 